\title{
Dependencia jurisdiccional del municipio castellano moderno
}

\author{
Juan Manuel Magan Garcia
}

INTRODUCCIÓN

Parece evidente que las sociedades rurales han jugado un protagonismo relevante en el entramado histórico global de la Castilla moderna. A medida que se profundiza en el estudio de la historia rural se va descubriendo la singular interrelación que existió entre los hechos políticos generales y su repercusión práctica en la cotidianeidad del desenvolvimiento de las comunidades rurales. La capacidad de reacción del mundo rural frente a los grandes acontecimientos es lo que históricamente le ha venido posibilitando influir de manera decisiva en el mantenimiento, degradación o potenciación de los soportes estructurales que hicieron posible la evolución histórica de la sociedad en su conjunto.

Desde esta óptica hemos llevado a cabo recientemente un estudio ${ }^{1}$ en el que pretendíamos examinar las construcción social del aparato administrativo y de gobierno en los municipios de la comarca toledana de La

\footnotetext{
1 Se trata de un trabajo de investigación presentado en los cursos de doctorado de la UNED, bajo el titulo: Municipios y dependencia jurisdiccional en la Castilla Moderna. La administración y el gobierno municipal en los pueblos de La Sagra durante la Edad Moderna. El trabajo ha contado con la dirección del profesor don Juan Antonio Sánchez Belén. El presente articulo pretende sintetizar algunos de los aspectos incluidos en dicha investigación.
} 
Sagra ${ }^{2}$ durante la Edad Moderna, como comunidad agraria paradigma del mundo rural castellano moderno.

Básicamente nuestra investigación buscaba un doble objetivo: por una parte, escudriñar el organigrama administrativo y de gobierno de los municipios, a fin de conocer tanto las instituciones municipales, como el ámbito competencial de cada una de ellas en particular y del concejo en su conjunto, en tanto que ente de gobierno de las comunidades rurales; y,

2 La comarca toledana de La Sagra comprende actualmente 28 pueblos, que en conjunto abarcan un espacio geográfico compacto que sólo supone el 6 por 100 del actual territorio provincial. Se situa en las tierras de la margen derecha del Tajo, siendo sus límites el cauce del Jarama-Tajo al Este, la margen izquierda del Guadarrama al Oeste, el límite provincial entre Toledo y Madrid al Norte, y el del municipio toledano al Sur.

En el mapa que sigue se especifica la situación de los términos municipales que constituyen la comarca, de forma esquemática.

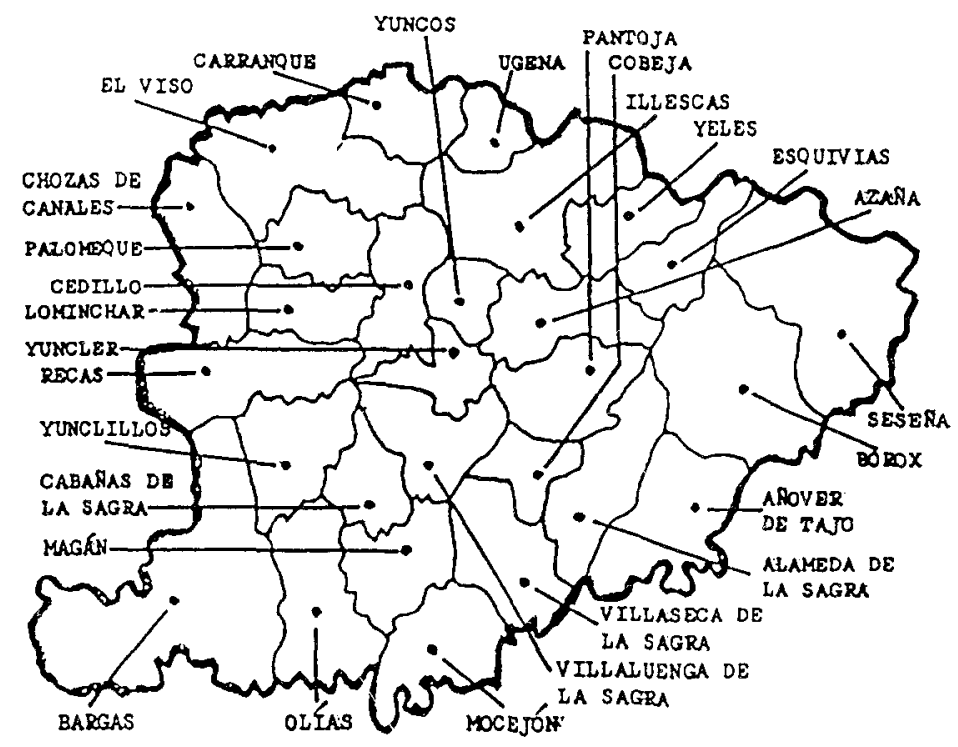

Hay publicados diversos estudios de carácter histórico y geográfico sobre la comarca de La Sagra, debidos a Isabel Carrillo, Vicente Rodríguez y Ramón Sánchez. Ninguno de ellos coinciden a la hora de delimitar el espacio comarcal, siguiendo cada uno criterio diverso en su conceptualización. Yo mismo aporto una definición comarcal que no es coincidente con ninguna de las ya enunciadas; sigo criterios exclusivamente históricos al aportar mi propuesta, que no hace al caso explicar aqui. 
por otra parte, descubrir la identidad de los grupos, estamentos e instituciones interesados en el control de los concejos.

Ambos objetivos los hemos pretendido circunscribir en otro más amplio: la profundización en el conocimiento de los regímenes dominicales en su evolución durante la Edad Moderna.

Así pues, el planteamiento global de nuestra investigación se articuló en torno al estudio de la evolución de las diversas tipologías de dominio jurisdiccional a lo largo de la Edad Moderna, desde un enfoque municipalista, investigando las conexiones que al respecto existieron entre las competencias jurisdiccionales de los municipios y las de los titulares de cada modalidad dominical sobre el particular.

El resultado de nuestro trabajo ha sido un primer análisis del panorama municipal castellano, en relación con la dinámica dominical que a lo largo del período de estudio fue caracterizando a cada uno de los pueblos de la comarca de referencia; con él pretendemos contribuir al conocimiento de la historia del mundo rural de la Castilla moderna. En las páginas que siguen intentaremos sintetizar algunos de los asuntos más notables tratados en nuestro estudio, procurando subrayar las conclusiones más sobresalientes a las que hemos podido llegar en cada caso.

\section{DEPENDENCIA JURISDICCIONAL}

Queda fuera de toda duda el papel primordial que jugaron los concejos en la ordenación de la vida de las comunidades rurales castellanas en la Edad Moderna, como entes públicos para la administración y el gobierno de los pueblos. Tal debió ser su importancia que múltiples instancias extramunicipales mostraron un constante interés por conseguir el control de sus estructuras orgánicas, como fórmula para asegurar la salvaguarda de sus numerosos intereses económicos radicados en el agro castellano.

En este sentido, el discurrir de los tiempos conocerá una progresiva pugna entre dichas instancias extramunicipales -en nuestro caso, principalmente el Ayuntamiento, la Iglesia y la nobleza de la ciudad de Toledo- y las nacientes oligarquias locales aglutinadas en torno a reducidos núcleos de vecinos hacendados, los cuales no cejarán en su empeño por fomentar en sus vecindarios respectivos crecientes sentimientos de autonomía, que no harán sino enmascarar sus ansias de control exclusivo de la política municipal. Los intereses en juego justificaban sobradamente por si solos la pugna por dicho control municipal. 
Dicha tensión, acelerada a partir de los años postreros del Quinientos, irá pareja a los sucesivos conflictos entre las citadas instancias extramunicipales, que surgirán con anterioridad al inicio de la Edad Moderna, en una lucha incesante por lograr el prevalecimiento de sus respectivos intereses en el mundo rural castellano. La propia evolución de tales conflictos pondrá de relieve en cada momento el potencial politico de que gozaron, actuando como indicador de la posición política en que se encontraron a lo largo de la Edad Moderna.

Tomando como punto de referencia la paulatina disgregación del realengo comarcal y la evolución de cada pueblo en lo relativo al régimen dominicial en que se inscribió durante el período de análisis, hemos podido constatar la tensión constante de los municipios en su aspiración por lograr y mantener las máximas cotas de autonomia con respecto a cualquier otra instancia de poder ajena. Esta meta es compartida por la práctica totalidad de los pueblos, que conjugaban en su mayoría su economía autárquica con la autogestión económica y autofinanciación de sus necesidades hacendisticas, en claro contraste con su dependencia jurisdiccional. Tal circunstancia vino propiciando la prevalencia de intereses ajenos a los de los vecindarios en la mecánica administrativa y de gobierno de la totalidad de los municipios, provenientes de las instancias que ostentaban el control jurisdiccional de los pueblos: las ciudades, la nobleza y la Iglesia.

La provisión de oficios concejiles fue el más preciado instrumento en esa dinámica de control indirecto de los municipios. Aunque se dio una aparente disparidad de formulaciones locales en todo lo tocante a los esquemas organizativos de los concejos, propiciada por el supremo imperio de la norma consuetudinaria y por la ausencia de unas disposiciones legales uniformadoras, en lo esencial hemos constatado que los oficios concejiles fueron usados como principal recurso para el control de los vecindarios, tanto social como económico. De ahí la relevancia que tuvo todo lo relacionado con la provisión de oficios, motivo hasta frecuente de reiterados pleitos, e incluso de alborotos y algaradas populares.

Es éste un asunto medular en lo que se refiere a la diversa configuración dominical de los municipios. Las diferencias en el procedimiento de elección de los munícipes es un indicador singular de la incidencia en la vida cotidiana de los pueblos por parte de los distintos titulares dominicales.

En pleno siglo Xvi detectamos en las villas de señorio nobiliario sagreñas una participación netamente autoritaria de los señores jurisdiccionales en la designación de los oficiales de los concejos bajo su dominio, característica que era compartida por los titulares de la Encomienda Ma- 
gistral sanjuanista de El Viso respecto de los pueblos adscritos a su jurisdicción. Estos procedimientos autoritarios mermaban sobremanera la libertad y autonomía de los municipios, en beneficio de las prerrogativas señoriales. Se procuraba de este modo el mantenimiento de la administración municipal al servicio del titular del señorio en cuestión, lo que hizo que los vecindarios chocaran a menudo con sus representantes en el concejo.

En claro contraste, los pueblos realengos bajo los corregimientos de Toledo e lllescas usaban de fórmulas menos autoritarias, siendo lo común la designación de justicias por los corregidores, que solian confirmar los cargos de acuerdo con el nombramiento duplicado que los propios concejos les remitían. El procedimiento empleado en algunos núcleos del alfoz toledano era aún más independiente ya que gozaban de la prerrogativa de autoelección sin injerencia alguna de la ciudad.

Sin embargo, la participación de estamento diverso al consistorio toledano en los lugares sagreños de su jurisdicción implicó el uso de fórmulas autoritarias en la dinámica de designación de oficios, muy particularmente en los pueblos en los que esta práctica constituía el núcleo de la participación del deán y cabildo catedralicio de la Ciudad Imperial en su configuración jurisdiccional.

Este esquema se mantiene casi inalterable a lo largo de los siglos XVII y XVIII, si bien hay que hacer algunas matizaciones al respecto. Asi, las villas realengas eximidas gozarán de absoluta independencia en la designación de sus municipes, mientras que las sometidas a régimen señorial por efecto de su adquisición por particulares, mantendrán sistemas semidemocráticos de presentación de candidaturas duplicadas, excepto en los pueblos en los que el titular hubiera comprobado la jurisdicción de tolerancia, en cuyo caso tenía plena libertad para nombrar los oficiales del concejo a su antojo.

En las villas de dominio señorial tradicional, asi como en los pueblos en los que la Iglesia de Toledo contaba con la potestad de confirmación de autoridades municipales, los procedimientos fueron paulatinamente derivando hacia fórmulas que permitían mayor participación de los concejos en la elección de sus justicias, produciéndose una progresiva disminución del intervencionismo del deán y cabildo toledanos y de los señores jurisdiccionales en su caso en la designación de oficios.

La investigación llevada a cabo sobre la provisión de oficios nos permite concluir que este aspecto se vino entendiendo por los vecindarios como el de mayor relevancia a la hora de frenar la influencia de los agentes extramunicipales interesados en el gobierno de sus concejos; de ahí la pugna por lograr la adquisición y perpetuación en los oficios munici- 
pales protagonizada por los hacendados locales de los pueblos realengos, que vieron en este negocio una eficaz fórmula para neutralizar la influencia de su matriz, desviando así para su provecho las prebendas inherentes al control de los concejos, particularmente en todo lo referente al abasto, aunque sin despreciar el resto de las amplias competencias derivadas del control jurisdiccional de los municipios. Si bien los oficios de alcaldes ordinarios no podian acopiarse por via de compra, en la práctica el control de las regidurías conllevaba el privilegio de designación de tales oficios, muy particularmente a partir de la generalización del procedimiento de elección mediante concejos secretos.

La práctica de la compra de oficios concejiles en el realengo significó un agente muy activo en el afianzamiento de las nacientes oligarquías locales en el agro castellano, a la par que generó un desenfrenado fermento de la corrupción administrativa. Así lo denuncia el licenciado Jerónimo Castillo de Bobadilla, con la cáustica ironía que le caracteriza:

«Pregunto yo: ¿en qué se funda el que vende toda su hacienda para comprar un regimiento; y el que no tiene que vender toma el dinero a censo para ello, no siendo el salario del oficio de más de 2000 ó 3000 maravedis? ¿Para qué tanto empeño para tan poco provecho? Fácil es de responder: que lo hace para traer sus ganados por los cotos, para cortar los montes, cazar y pescar libremente, para tener apensionados y por indios a los abastecedores, y a los oficiales de la república, para ser regatones de los mantemientos y otras cosas en que ellos ponen los precios, para vender su vino malo por bueno, y más caro, y primero para usurpar los propios y pósitos y ocupar los baldios, para pedir prestado y nunca pagar, para no guardar tasa ni postura común, para vivir suelta y licenciosamente, sin temor de la justicia y para tener los primeros asientos en los actos públicos y usurpar indignamente los ajenos honores..., ${ }^{3}$.

La copiosa documentación examinada en el Archivo General de Simancas ${ }^{4}$, además de hacernos colegir que el fenómeno incidió de forma sustancial en La Sagra, nos descubre una nueva faceta: la compra de oficios no revirtió sólo en el acaparamiento de los cargos en manos de los hacendados locales, sino que vino a significar también la perpetuación en los mismos de algunos de los vecinos toledanos afincados en los pue-

\footnotetext{
${ }^{3}$ Castillo de Bobadilla, J., Politica para corregidores y señores de vasallos. Madrid 1978 (ed. facsímil de la de 1704), parte II, libro III, capitulo VIII, pág. 193.

4 Archivo General de Simancas (AGS), Cámara de Castilla. Consumo y perpetuación de oficios, leg. $3,4,5,11,15,22,23$ y 39.
} 
blos realengos de la comarca, quienes vieron así reforzada su presencia en los concejos para mayor provecho de sus intereses, principalmente en los lugares circundantes de la capital. Sirva de ejemplo lo ocurrido en Olías en 1573: Diego Grandío y Beltrán de San Pedro -toledanos con morada en dicho lugar - adquirieron sendas regidurias, por las que cada uno abonó 200 ducados; días después de esto, ocho vecinos hacendados del lugar compran cuatro regidurias mancomunadamente, al precio de 800 ducados. Queda así en evidencia el interés de los lugareños por contrarrestar la influencia de los toledanos. En Bargas, por su parte, siete vecinos de Toledo alli heredados adquirieron en 1574 sendas regidurías, por las que cada uno abonó 200 ducados... Parece evidente el interés de este colectivo por copar los cargos concejiles ${ }^{5}$.

Esta dinámica de venta de cargos municipales, de las que escaparon los concejos de los municipios sanjuanistas, los de dominio nobiliario -incluidos los de señorialización tardía cuyos titulares poseían la merced de tolerancia-, y aquellos en los que intervenía el cabildo toledano en el nombramiento de oficios, resultó muy eficaz como paso previo a la potenciación de la emancipación de los pueblos por la vía de su exención. De igual modo, dicha privatización de los cargos concejiles redundó en la culminación del proceso de oligarquización de los concejos, con el resultado final de convertirlos en meros negocios al servicio de los intereses privados de la minoría pudiente en cada pueblo, en una clara y manifiesta supremacia de la corrupción administrativa, que conllevó una galopante esclerotización de la participación política de los vecinos en sus ayuntamientos.

Los efectos distorsionantes de tal circunstancia encuentran eco en numerosos informes, de los que buen ejemplo es el emitido en 1797 por José García, a la sazón procurador síndico general de Mocejón:

\footnotetext{
"Hace muchos años que una familia de las más pudientes y de consiguiente prepotente y temible, de que el pueblo causa a su común y particulares los mayores daños, perjuicios y extorsiones, aprovechándose con su copioso número de ganados de los pastos comunes, cual si para ellos fuesen únicos, dejándoles enteramente destruidos: así como los de agostadero de este año, produciendo sus diversiones daños considerables en las siembras particulares, sin que haya quien de miedo lo reclame, ni tampoco la desigualdad con que se hacen los repartimientos de las cargas y contribuciones anuales, eventuales y regias, pues o se les exceptúa de ellas, o no se les imponen como a los otros vecinos, sin
}

\footnotetext{
5 Ibidem, leg. 4 y 23
} 
que haya ninguno que a nada de esto se oponga, denuncie, ni remedie, porque los que regentan los empleos y oficios son individuos de la familia prepotente, sus parientes, aliados o dependientes, no alcanzando el remedio" ${ }^{6}$.

Un precedente claro de este movimiento hacia la aristocratización del poder municipal lo constituye la práctica de la mitad de oficios; precisamente la comarca estudiada, caracterizada históricamente por la escasa representación numérica de hidalgos en su suelo, es ejemplo apropiado para argumentar la injusticia que esta práctica implicaba. La defensa a ultranza de sus prerrogativas por parte de la exigua masa de hidalgos sagreños pone de relieve las indudables excelencias que éstas debian reportarles. El beneficio que obtenian mediante el ejercicio del control del municipio desde los oficios concejiles, justificaba sobradamente su interés por acaparar cargos «al servicio del pueblo», en flagrante desigualdad respecto de sus vecinos pecheros.

La dependencia jurisdiccional de los municipios castellanos propició en todos los casos un soporte idóneo desde el que sus beneficiarios aseguraban sus rentas agrarias, lo que coadyuvó a la progresiva descapitalización del campo castellano, al detraer las ganancias en beneficio de intereses ajenos al ámbito rural en el que se generaban. Con otras palabras, tanto la nobleza con dominios señoriales -excluida la titular de señorios tardios-, como la Iglesia y la ciudad de Toledo, usaron sus privilegios jurisdiccionales como útil mecanismo para salvaguardar los intereses económicos radicados en suelo comarcal, cuyos ingentes beneficios muy escasamente revertian en el fomento de las economías rurales, constituyendo asi un claro ejemplo de lo que podemos denominar parasitismo económico. De ahi la favorable acogida que, en el ámbito realengo, experimentaron en los pueblos las propuestas de exención fomentadas por los grupos oligárquicos de cada municipio, aun a sabiendas de que tales operaciones implicaban un esfuerzo económico gravoso para el común de los vecinos.

Sin embargo, esta lógica no desembocó en movimientos antiseñoriales en las villas acogidas a régimen señorial con implicación bajomedieval, salvo rarisimas excepciones ${ }^{7}$, tal vez sencillamente por la ausencia

\footnotetext{
- Archivo Histórico Nacional (AHN), Consejos, leg. 1983. Citado por SÁnchez GonzAlez, Ramón, Economia y sociedad en el Antiguo Régimen. La comarca de La Sagra en el siglo xvil. Toledo 1992, pág. 426.

El lugar de Palomeque, aldea de la jurisdicción de El Viso, intentó su segregación de la bailia de Olmos en el año 1736. La operación resultó frustrada (Archivo Histórico Provincial de Toledo, $\mathrm{H}-495)$.
} 
de élites oligárquicas distintas de los propios señores jurisdiccionales, o tal vez porque éstas, de existir, gozaran del amparo señorial, en una situación de comensalismo provechoso para ambos.

\section{EVOLUCIÓN DE LOS REGIMENES DOMINICALES}

Los procesos de exención, como los de ventas de lugares, afectan a los dominios realengos, muy especialmente al alfoz de Toledo a raíz de la progresiva degradación y decadencia de la ciudad, fenómeno del que puede considerarse a la vez causa y efecto.

La segregación en ambos casos implicó, en la práctica, un mero trasvase centrado en el ámbito competencial de los derechos jurisdiccionales, produciéndose una transmisión de las facultades jurisdiccionales de la ciudad de Toledo, o de la villa de Illescas en su caso, a los concejos o a los señores compradores.

Por lo que se refiere al proceso de señorialización tardía, nunca supuso adquisición de prerrogativas de carácter solariego, por lo que el contenido económico fue a la postre muy escaso, quedando todo por lo general restringido a la pompa huera de los títulos. Tal vez ello explique el escaso interés mostrado por la nobleza con señoríos en la comarca por ampliar sus dominios jurisdiccionales en semejante coyuntura.

Pocas repercusiones pudieron tener en la vida cotidiana de los municipios afectados los efectos derivados de su exención o de su venta a particulares, si se exceptúa el subsiguiente a su desvinculación del control administrativo de Toledo, muy debilitado ya en el siglo xvI por mor de la crisis de la ciudad.

Un análisis comparativo revela una mayor satisfacción en los vecindarios de las villas eximidas con respecto a los de los pueblos señorializados, lo que se pone más de relieve si cabe en aquellos en los que la exención viene como consecuencia del uso del derecho de tanteo, tras un período de señorialización previo.

Parece que los vecindarios afectados por la señorialización tardía asumieron el cambio de status con resignación o, a lo sumo, como mal menor. Todos ellos eran municipios de corta población, en los que su señorialización no implicó sino un cambio de dueño, pues como tal se comportaba Toledo con sus aldeas. Empero, el reingreso a su condición realenga por parte de algunos de ellos nos pone sobre aviso de la predilección de los vecindarios por esta última fórmula dominical, adoptada a pesar del endeudamiento que era inherente al proceso de exención. 
Indudablemente, la emancipación de los pueblos redundó siempre en beneficio de las oligarquias locales principalmente, que pasaban a sustituir a la ciudad de Toledo o a los señores jurisdiccionales en su papel de control implicito de los municipios, en un proceso de fortalecimiento que confluye en un punto de encuentro entre la depauperada Real Hacienda y los grupos sociales en ascenso. Se estaba alentando, pues, tal vez involuntariamente, el afianzamiento de un caciquismo local que acabaría copando la administración de los municipios.

Toledo, por su parte, siempre accionó los mecanismos burocráticos al uso para evitar la disgregación de su alfoz y consiguiente enajenación de su patrimonio jurisdiccional de los pueblos adscritos a su término; pero no siempre actuó con igual interés, a juzgar por los resultados. Hemos constatado una mayor preocupación por preservarse para sí los pueblos más próximos a la ciudad, cuyas economías guardaban una relación más estrecha con los abastos más perentorios pues sus habitantes, además de ser en los que mayor densidad de heredades pertenecientes a vecinos de Toledo registraban en la comarca ${ }^{8}$.

Parece claro en todo caso que el conflicto inherente a la exención de los pueblos realengos sagreños se planteó básicamente entre las pujantes oligarquías locales y el patriciado urbano que los pretendía gobernar para su provecho desde los órganos de control jurisdiccional de la ciudad.

Las condiciones en que se concertaba la operación garantizaban la situación propicia para desligarse totalmente de la tutela jurisdiccional a la que los pueblos realengos se hallaban sometidos. Puede servirnos como ilustración Añover de Tajo; este lugar, sujeto al dominio jurisdiccional de la Ciudad Imperial hasta 1639, logró su exención al amparo de lo dispuesto en la Real Cédula de 11 de marzo de dicho año, por la que se facultaba a la Corona a vender 800 vasallos. El acceso al status de villa eximida se logra por Añover de Tajo en la última quincena de diciembre del referido año; las condiciones pactadas para efectuar la transacción, entre las cuales aparecen las cláusulas por las que se autoriza al concejo a adoptar las medidas oportunas en orden a acopiar el numerario preciso con el que hacer frente al pago de los 16800 ducados en que se fijó el servicio que habia de abonarse a la Real Hacienda, especificaban que la exención no implicaría la dejación de los compromisos que los vecinos

\footnotetext{
- Hemos documentado ampliamente la resuelta iniciativa de la ciudad de Toledo llevada a cabo con éxito para impedir la segregación de su alfoz de varios pueblos sagreños, en actitud decidida, como la mostrada en diversas ocasiones al oponerse a la enajenación y exención del lugar de Mocejón, que junto con Magán y Bargas eran los principales abastecedores de pan cocido para la ciudad.
} 
tenían contraídos con el Conde de Arcos, conforme a la concordia que entre ambas partes firmaron, por la que se habian obligado a pagar al de Arcos la décima parte del producto de sus cosechas. El resto de las condiciones incidian directamente en la cuestión de la autonomía jurisdiccional; desglosadas y en sintesis eran éstas:

1. ${ }^{a} \quad$ Que el rey exime al lugar de Añover de la ciudad de Toledo, «haciéndole villa aparte sobre sí y con su término, jurisdicción civil y criminal, mero mixto imperio, señorio y vasallaje, con primera y segunda instancia, penas de cámara y sangre y arbitrarias".

2. ${ }^{2} \quad$ Que el concejo tenga la potestad de nombrar «alcaldes ordinarios, regidores, alguacil mayor que haga oficio de fiscal y otro alguacil, dos procuradores para pleitos y los demás oficiales que el concejo acostumbra a nombrar, excepto escribanos, por cuanto éstos los tienen ya comprados y pagados".

3. ${ }^{\text {a }}$ Que el nombramiento se haga en "ayuntamiento secreto", con participación y voto de alcalde, regidores y procurador general en ejercicio, junto con el alcalde y los regidores del año anterior, quienes nombren candidatos duplicados, procediendo luego a sorteo de oficios, "con lo cual quede hecha la elección sin otra aprobación alguna».

4. ${ }^{a} \quad$ Que para «en cuanto la segunda instancia, en lugar de alcalde de alzadas y apelaciones, lo haya de ser el ayuntamiento", que a tal efecto consiste en dos regidores más tres diputados. Actúan en las causas de "menor cuantia», procediendo en las demás en «la forma ordinaria", siempre "quedando libre a las partes el recurso a la Chancilleria».

5. ${ }^{a} \quad$ Que en lo tocante a las residencias, sea el alcalde entrante quien la tome a la justicia saliente ${ }^{9}$.

La oportunidad de conseguir plena autonomía mediante la adquisición del privilegio de exención fue aprovechada por aquellos pueblos que contaban con riqueza y población suficientes para soportar el oneroso trámite de la segregación. Las exenciones de los lugares de nuestra comarca se verificaron siempre de manera pacifica, si bien gravaron pesadamente las haciendas de los municipios con censos que para comprar su segregación se vieron obligados a contraer. Este endeudamiento, del que salen

\footnotetext{
s Archivo Municipal de Añover de Tajo. Privilegio de la villa de Añover de Tajo de exención de la jurisdicción de la ciudad de Toledo. 1639. (ms.)
} 
beneficiados por lo general diversas instituciones eclesiásticas, no supuso en los pueblos de La Sagra un escollo insalvable que les impusiera su autoventa, enajenando de nuevo su recién ganada autonomía, como asi ocurriera en otros ámbitos geográficos de Castilla, según documenta Dominguez Ortiz ${ }^{10}$.

La exención de lugares de señorio nobiliario sólo se dio en los pueblos tardiamente señorializados, único caso en el que se contemplaba esta posibilidad, gracias al ya aludido derecho de tanteo. En ocasiones la operación no sólo implicaba una transacción económica, sino que abarcaba acuerdos previos entre el titular del señorio y el propio municipio. Tomaremos como referencia de ello el proceso de exención de Yuncler, efectuado en los primeros días de 1638, tras un breve período de dominio señorial de menos de un año. La retrocesión se efectuó cumpliendo los tres requisitos previamente convenidos entre el concejo de Yuncler y don Francisco Melchor de Luzón y Guzmán, su señor jurisdiccional: primero, que dicho don Francisco Melchor hacía «dejación del señorio, jurisdicción y vasallaje de la villa de Yuncler, y sus alcabalas y todo lo demás comprendido en las escrituras de venta", sin reservarse derecho alguno a ello; segundo, que la escribanía de la villa quedara conforme a la situación en que estaba en el momento previo a la venta del lugar; y tercero, que Yuncler se obligara a pagar el situado que tenían sus alcabalas, a contar desde el primer día de 1638 en adelante ${ }^{11}$.

Cabe pensar que este tipo de exigencias impuestas por el titular del señoric tuvieran un carácter disuasorio, planteadas así por estorbar la autocompra de los pueblos. Desde luego parece evidente que por parte de los señores jurisdiccionales hubo un rechazo claro de estas operaciones, de lo cual es muestra la actitud del conde de Saceda en el momento en que Ugena pretende su reingreso al realengo. La documentación del pleito de tanteo recoge un informe elevado por el fiscal del Consejo de Castilla fechado en Madrid, a 2 de junio de 1775, en el que se da cuenta de las tensiones que en el seno del concejo de Ugena provocó el citado conde de Saceda en orden a impecir el éxito de la operación de tanteo; en dicho informe el fiscal expresa con toda nitidez la postura inequivoca del vecindario:

"... sólo desean reintegrarse en el suave dominio de la Corona, sacudiendo el yugo y especie de servidumbre que les ocasiona la sujeción a un dueño particular, que promueve únicamente sus intereses..." ${ }^{12}$.

\footnotetext{
10 Dominguez Ortiz, A., "Ventas y exenciones de iugares en el reinado de Felipe IV", Anuario de Historia del Derecho, XXXIV, 1694, págs. 195-196.

11 AGS, Mercedes y Privilegios, leg. 361. 12.

12 AHN, Consejos, leg. 27709. Citado por Moxó, S., Los antiguos señorios de Toledo. Toledo 1973, pág. 297
} 
La señorialización del realengo en cualquier caso echó por tierra en los pueblos afectados sus deseos de autonomia jurisdiccional, muy especialmente en aquellos en los que el titular poseia la merced de tolerancia, prerrogativa que no quedaba incluida en la compra del señorio de la aldea. Sólo en este supuesto cabe afirmar que el dominio jurisdiccional del señor era absoluto. Sacaremos a colación el ejemplo de Lominchar, aldea realenga del alfoz de Toledo vendida en 1642 a don Francisco Velázquez Minaya por 2.625.010 maravedís. En 1679 el titular del señorio de esta villa era don Juan Antorio López de Zárate, quien adquirió a la Real Hacienda el privilegio de tolerancia, gracia por la que abonó un servicio de 200.000 maravedís, a razón de 4.000 maravedís por vecino. La carta de compra de esta merced, fechada en Madrid, a 18 de febrero de 1679, recoge las condiciones estipuladas, con detalie expreso de los derechos que comprendia el ejercicio de dicha prerrogativa, los cuales son en síntesis los siguientes:

1. ${ }^{a} \quad$ Que el comprador y sus sucesores en el privilegio «por sí solo y sin proposición y nombramiento de la dicha villa, los ha de poder nombrar (a los oficiales del concejo) y nombre en cada un año por principio de él, o cuando quisiere y por bien tuviere, dando a cada uno su título".

2. ${ }^{a}$ Que dicho privilegio lo recibe "por título de venta perpetua, de juro de heredad, para ahora y para siempre jamás", sin que los vecinos de la villa nunca puedan entrometerse en ello.

3. Que la corona no puede en adelante acrecentar los oficios del concejo de la villa, ni vender, ni hacer merced de ellos en ninguna circunstancia.

4. ${ }^{2} \quad$ Que el titular del privilegio «o sus sucesores en la dicha villa y jurisdicción ha de poder remover y quitar a todos y cualesquier de ellos, con causa o sin ella, todas las veces que les pareciere, como dueño de los dichos oficios y del nombramiento, jurisdicción, uso y ejercicio de ellos, en la forma que más quisiere y convenga a su derecho» ${ }^{13}$.

Si la señorialización de las aldeas nunca fue deseada por los propios vecinos, en mucha menor medida lo fue por las cabezas de regimiento a las que estaban adscritas, por razones obvias.

\footnotetext{
${ }^{13}$ AGS, Mercedes y Privilegios, leg. 354, n. ${ }^{\circ} 12$.
} 
Sabemos de la oposición de la influyente villa de lllescas a la señorialización de su tierra por un valioso y amplio documento custodiado en el Archivo General de Simancas ${ }^{14}$. Los temores de disgregación de sus aldeas -Ugena, Torrejoncillo y Valaguera - se detectan en la Villa Imperial ya a finales de 1583, apenas una década después de su desmembración del dominio de la mitra de Toledo.

De inmediato se acuerda una convocatoria de concejo abierto en el que sea tratado el asunto y se adopten medidas drásticas para impedir lo que para el vecindario suponia la ruina de su prosperidad. Tras diversas discusiones, el ayuntamiento de la villa fija el convite para el dia 18 de octubre del referido año 1853; el concejo se celebra en esa fecha presidido por el corregidor. Ediles y vecinos comienzan a barajar las dos opciones que se presentaban como más viables; la disyuntiva se cifraba en promover el reingreso de la villa y su tierra al señorio de la dignidad arzobispal de Toledo, o bien asegurarse su no segregación del realengo mediante el pago de un rescate a la Corona, como ya lo hiciera en su momento la propia ciudad de Toledo para evitar la segregación de su alfoz jurisdiccional ${ }^{15}$.

La lectura de la amplisima acta de aquel concejo abierto, por demás interesante y enjundioso, revela la existencia de las dos posturas divergentes en el vecindario illescano, cuyos defensores ponen de manifiesto en cada caso las excelencias de su mayor ventaja, echando mano de argumentos basados en la experiencia histórica por ellos vivida en los tiempos pretéritos y presentes.

La disparidad de opiniones se somete a un proceso de votación nominal, en el que cada vecino se va decantando por una u otra opción, al tiempo que insiste en los argumentos justificativos de su voto. Procedimiento similar se sigue en las aldeas de la tierra. En todas ellas, la voluntad de los vecindarios se decanta mayoritariamente por su mantenimiento en el realengo y el pago del rescate primando claramente la ponderación de las ventajas del régimen realengo, aunque ello comportara el desembolso de una importante suma de dinero que repercutiría en las haciendas de todos los vecindarios. lliescas y sus aldeas se compro-

${ }^{14}$ Ibidem, leg. 361, n." 3.

15 Tenemos noticias de cierta Real Cédula firmada del emperador Carlos en 1537 «tocante a que no se puedan vender ningunos lugares de la jurisdicción: ganada por Toledo, previo pago de cierto servicio de 12.000 ducados a la Real Hacienda. (Archivo Municipal de Toledo. Acuerdos, ALM, sala $V .{ }^{a}$ est. $^{a}{ }^{1}{ }^{a},{ }^{\circ}{ }^{\circ} 72$, fol. $354 \mathrm{v}$ ). Lamentablemente aún no he podido dar con el texto de la merced a que se refiere, aunque las alusiones a dicho documento son muy frecuentes en los libros de actas capitulares del ayuntamiento de Toledo. 
metian a servir a Su Majestad con 15.000 ducados, que se sufragarian mediante repartimiento cen cualquier vecinos de la villa y su tierra y las otras personas que tienen bienes y hacienda raiz de ella, aunque sean clérigos e hidalgos y vecinos de otros pueblos».

Las condiciones del pago del rescate y los compromisos que adquiría la corona en recompensa quedaron aprobados oficialmente en un documento redactado en Madrid, a 25 de abril de 1584. En 27 de noviembre de 1599 Felipe III firmará una confirmación de la merced de no segregación de Illescas y su tierra, otorgada por su padre. El compromiso se mantiene hasta los años finales del reinado de Felipe IV, pero su administración, ávida de numerario, lo rompe, poniendo en venta la totalidad de las aldeas que hasta entonces estaban sometidas a la jurisdicción de Illescas. Sólo la propia Villa Imperial logró eludir su segregación del realengo; sus aldeas fueron adquiridas por el conde de la Roca en $1660^{16}$.

Por su parte, el proceso de desmembración del realengo concejil de Toledo en La Sagra tuvo su origen en la Edad Media, iniciándose como consecuencia de sucesivas donaciones regias a la Iglesia de Toledo, a las órdenes militares de San Juan y Calatrava, y a la nobleza toledana. Especial incidencia tuvo al respecto la política de señorialización trastamarista, así como la prolongada acción usurpadora que caracterizó a las últimas centurias medievales y a las primeras décadas de la Edad Moderna.

Estas circunstancias, unidas a las acarreadas por efecto de las exenciones y del proceso de señorialización tardia, harán que se produzca una enorme versatilidad de los regímenes dominicales por los que fueron atravesando los pueblos sagreños, aspecto que caracterizará a la comarca en su conjunto. Eludiremos la pormenorización del proceso evolutivo seguido al respecto, pues sería prolijo en exceso; será suficiente detallar en los mapas ${ }^{17}$ que van a continuación la situación en tres fases del período estudiado. En ellos se podrá contrastar los cambios operados a lo largo de la Edad Moderna, que, como se puede apreciar, afectan principalmente al área realenga de la cumarca.

Por lo que respecta a las exenciones y ventas de lugares, última circunstancia que motivó la modificación del panorama dominical en la comarca, tres aspectos incidieron en su puesta en marcha: por un lado, la

\footnotetext{
${ }^{16}$ AHN, Consejos, leg. 27709 y 11558. (Vid. Moxo, S., op. cit., págs. 223-229).

17 En estos mapas no quedan reflejados los términos que ocuparian las aldeas de Torrejoncillo y Valaguera, en la tierra de Illescas, pues en la actualidad son despobiados cuyos términos quedan en parte incluidos en la actual provincia de Madrid.
} 
MAPA N. ${ }^{\circ} 1$

Panorama dominical en la comarca de La Sagra.

Situación en el año 1550.

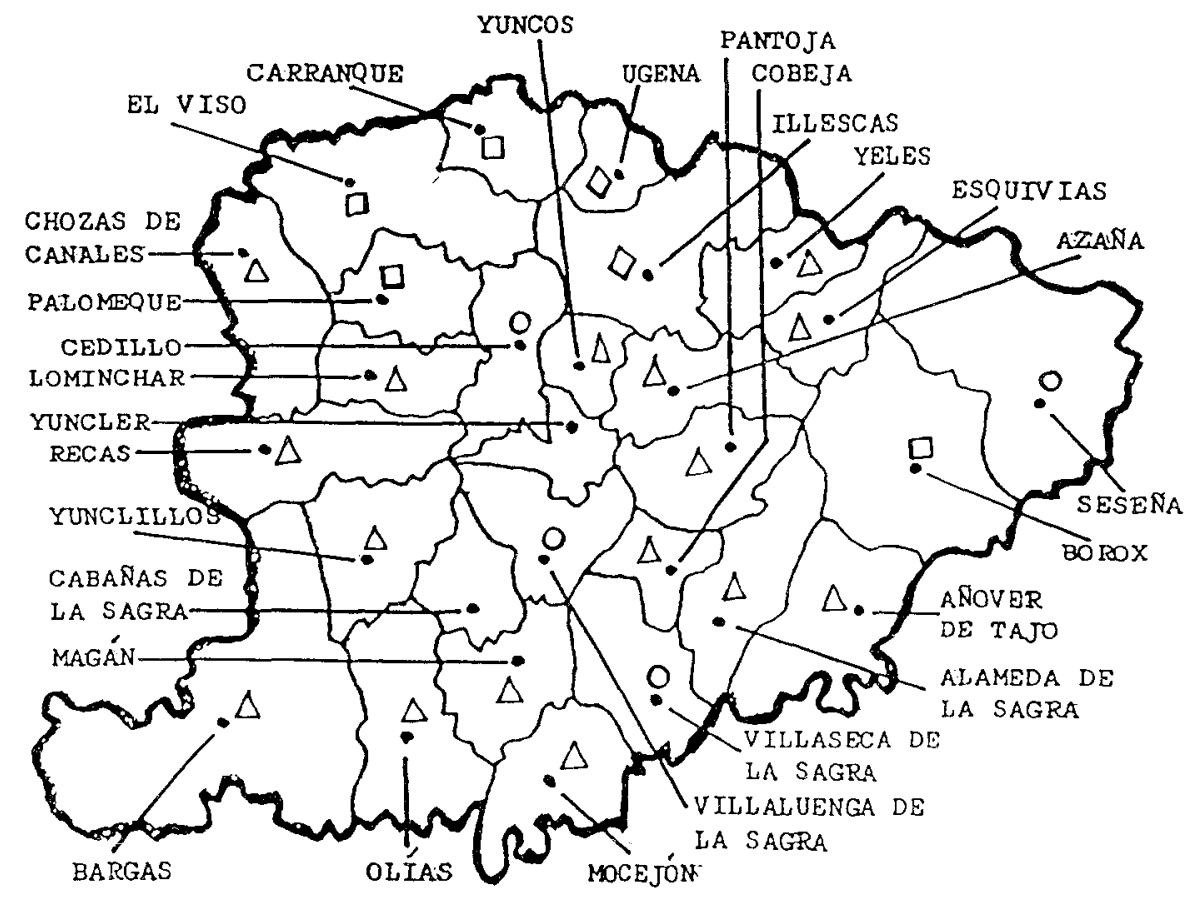

ÁREA DE SEÑORÍO

- Señorios nobiliarios medievales

$\square$ Señorios de Órdenes Militares.

$\diamond$ Señoríos de la Mitra Arzobispal de Toledo.

ÁREA DE REALENGO

$\triangle$ Realengo concejil de Toledo. 


\section{MAPA N. 2}

Panorama dominical en la comarca de La Sagra.

Situación en el año 1650.

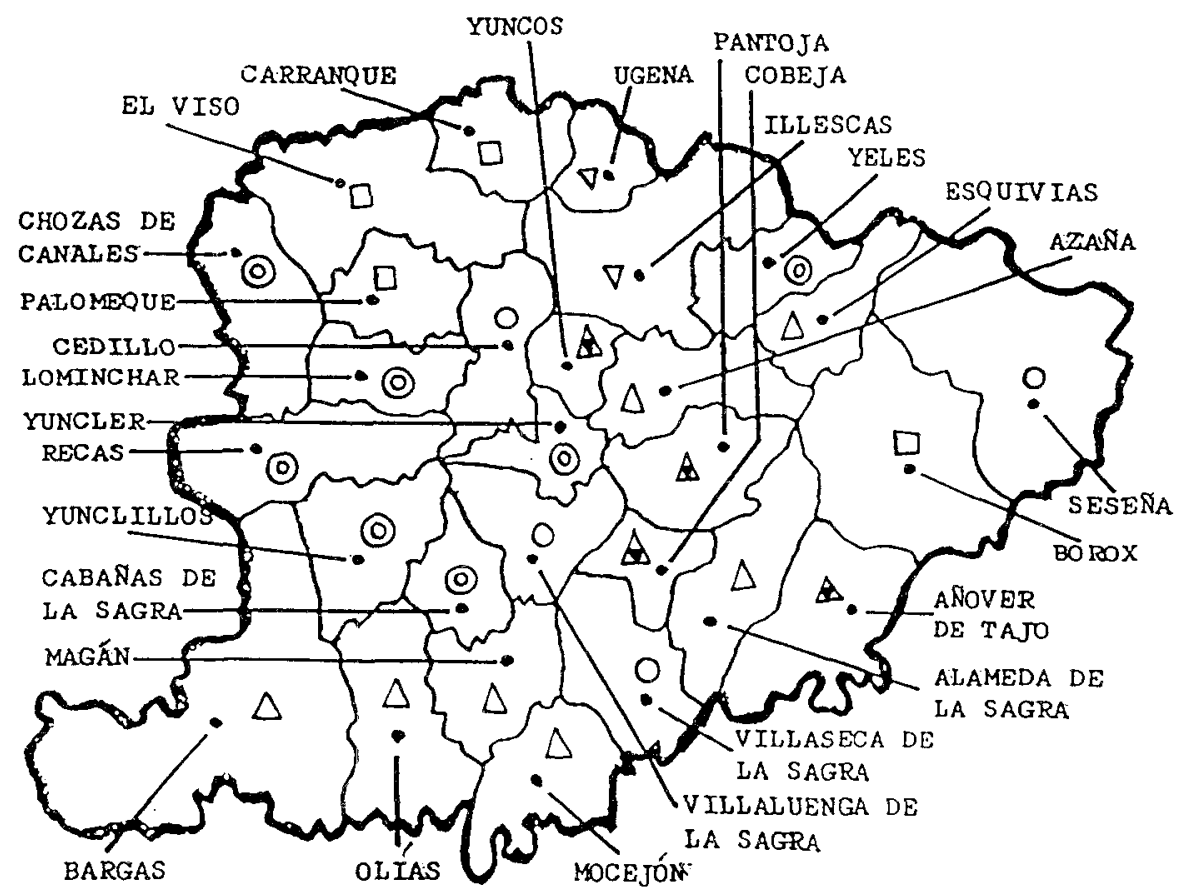

ÁREA DE SEÑORIOO

Señorios nobiliarios medievales.

(2) Señorios nobiliarios tardios.

$\square$ Señorios de Órdenes Militares.

ÁREA DE REALENGO

$\Delta$ Realengo concejil de Toledo.

$\nabla$ lllescas y su tierra.

$\Delta$ Villas eximidas. 
MAPA N. ${ }^{\circ} 3$

Panorama dominical en la comarca de La Sagra.

Situación en el año 1800

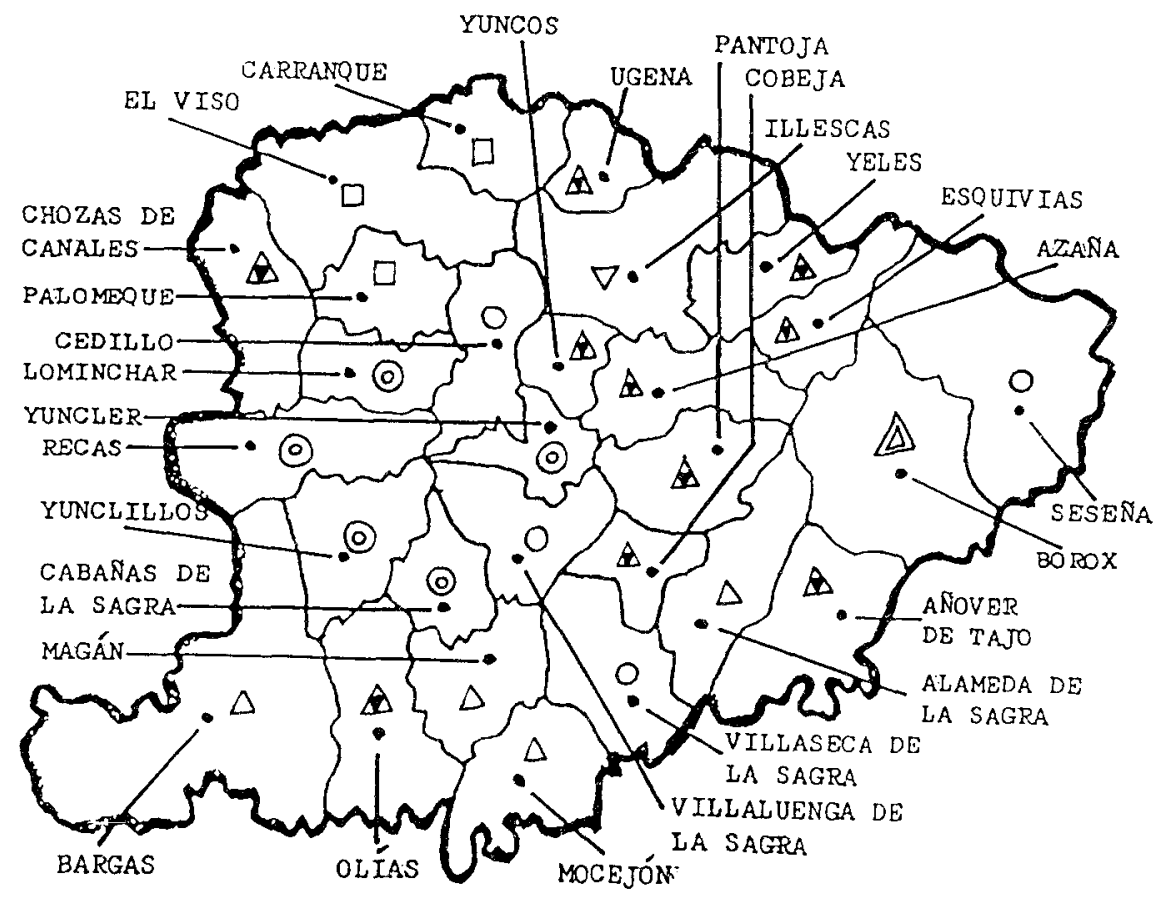

ÁREA DE SEÑORIOO

- Señorios nobiliarios medievales.

(2) Señorios nobiliarios tardios.

Señorios de Órdenes Militares.

\section{ÁREA DE REALENGO}

$\triangle$ Realengo concejil de Toledo.

$\nabla$ Alfoz de lllescas

$\Delta$ Villas eximidas.

$\triangle$ Gobernación de Aranjuez. 
iniciativa de la corona, obligada a adoptar medidas urgentes para el saneamiento de la Real Hacienda; por otro lado, el resurgir de una nueva aristocracia nobiliaria, sedienta de títulos y con una holgada situación económica; y, finalmente, la culminación de un proceso de oligarquización del poder municipal, cuyas élites promovieron con éxito en los pueblos las ansias autonomistas.

Este conjunto de circunstancias, unido a la decadencia en que se vio inmersa la Ciudad Imperial, favorecieron la drástica reducción del alfoz toledano en la comarca. De este modo, quedó casi extinguido el dominio jurisdiccional que venía asegurando a la ciudad tradicionalmente las premisas económicas y políticas precisas para argumentar su influencia en los asuntos del reino; $y$, por ende, quedó radicalmente menguado el protagonismo hegemónico que Toledo asumió durante siglos en los pueblos de su término, en los que determinaba de múltiples maneras la vida de sus vecindarios.

Lo acaecido en Toledo y en Illescas revela la impotencia en que se vieron tantas ciudades y villas castellanas frente al desaforado movimiento segregacionista de sus aldeas, propiciado por las urgencias financieras de la maltrecha Real Hacienda.

En suma, con la investigación realizada creemos haber puesto de manifiesto la decisiva participación que el mundo rural castellano tuvo en el sostenimiento político y económico de las ciudades, de la Iglesia y de la nobleza, en tanto que esferas de poder cimentadas en el agro caste!lano. En todo ello fue pieza clave el sometimiento jurisdiccional de los municipios, del que no escaparon los pueblos realengos. Estimamos que debe considerarse éste como uno de los aspectos de primer orden para la comprensión histórica de la Castilla rural en el Antiguo Régimen. 